\title{
Developmental Trajectories of Oppositional Behavior during Elementary School and Their Risk Factors
}

\author{
Marc Tremblay ${ }^{1}$, Stéphane Duchesne ${ }^{1}$, Frank Vitaro ${ }^{2} \&$ Richard E. Tremblay ${ }^{3,4}$ \\ ${ }^{1}$ Faculté des sciences de l'éducation, Université Laval, Québec, Canada \\ ${ }^{2}$ Psychoeducation Department, Université de Montréal, Montréal, Canada \\ ${ }^{3}$ Psychiatry Department, Université de Montréal, Montréal, Canada \\ ${ }^{4}$ University College Dublin, Ireland \\ Correspondence: Stéphane Duchesne, Département d'études sur l'enseignement et l'apprentissage, Faculté des \\ sciences de l'éducation, Local 934, 2320, rue des Bibliothèques, Université Laval, Québec (Québec) G1V 0A6, \\ Canada. E-mail: Stephane.Duchesne@fse.ulaval.ca
}

\author{
Received: February 17, $2013 \quad$ Accepted: April 7, $2013 \quad$ Online Published: April 16, 2013 \\ doi:10.5539/jedp.v3n1p234 URL: http://dx.doi.org/10.5539/jedp.v3n1p234
}

\begin{abstract}
Oppositional and defiant behavior (ODB) problems are among the most important behavior problems in school children. Understanding their trajectories during elementary school and conditional risk factors at school entry is essential for implementing effective preventive and corrective interventions. Behavior problems of a population sample (958 boys, 971 girls) attending public schools were assessed annually by teachers. Three groups were identified: High Opposition (HO; 14.5\%), Moderate Opposition (MO; 37.5\%), and Low Opposition (LO; 48.0\%) Children on the HO trajectory were found to be different from those on the MO and LO trajectories for numerous kindergarten risk factors: a) they tended to be boys with high family adversity; b) their mothers reported low warmth and high control; c) teachers rated them high on physical aggression, opposition, hyperactivity and low anxiety. Children who are likely to have chronic ODB throughout the elementary school years can be identified in kindergarten. Preventive interventions at school entry could probably help these children.
\end{abstract}

Keywords: opposition, trajectories, behavior, parents, childhood

\section{Introduction}

Oppositional behavior and defiance are two of the main reasons for referral to mental health services in the early school years (Gale, 2011; Kimonis \& Frick, 2010). In clinical terms, oppositional defiant disorder (ODD) is defined as a recurrent pattern of negativistic, defiant, disobedient, and hostile behavior toward authority figures that seriously interferes with social or school functioning. Research has shown that stable oppositional behavior can start by two years of age (Petitclerc, Boivin, Dionne, Zoccolillo \& Tremblay, 2009), persists during the elementary school years (Broidy et al., 2003; Harvey, Friedman-Weieneth, Golstein \& Sherman, 2007), and is often co-morbid with hyperactivity, aggression, and anxiety (Drabick, Bubier, Chen, Price \& Lanza, 2011; Munkvold, Lundervold \& Manger, 2011). Furthermore, opposition during childhood is predictive of a range of harmful consequences, including executive functioning deficits, conflicts with peers and adults, depression, suicidal thoughts, academic failure, vocational maladjustment, delinquency, and the development of antisocial personality in adulthood (Gale, 2011; Broidy et al., 2003; Burke, Waldman \& Lahey, 2010). Given the harmful effects on the lives of oppositional children and on the people around them, a better understanding of the individual differences in how these symptoms develop and their risk factors is needed in order to design preventive and corrective interventions.

To our knowledge, no population-based studies of boys and girls have traced the chronological development of opposition symptoms during the elementary school years. One study described the developmental trajectories of boys from low socioeconomic areas in a Canadian city followed from 6 to 15 years of age (Nagin \& Tremblay, $1999)$, identified "low opposition" (25\% of the sample), "moderate opposition" (46\%), "high opposition" (25\%) and "chronic opposition" (5\%) groups. Another used an accelerated (multicohort) longitudinal study of boys and girls between age 4 and 18 years in the Netherlands (Bongers, Koot, van der Ende \& Verhulst, 2004) identified 
six trajectories: almost zero opposition (7.1\%), decreasing opposition $(23.7 \%)$, increasing opposition at adolescence $(6 \%)$, moderately decreasing opposition (32.5\%), high-decreasing opposition $(24.2 \%)$, and high-persistent opposition (6.5\%). Boys were slightly overrepresented in the last two trajectories (around 53\%). More recently, a central component of ODD (i.e., disregard for rules) was described in a population sample of Canadian children followed from 29 to 74 months old (Petitclerc et al., 2009) described four groups who showed distinct and stable trajectories: very low $(9.1 \%)$, low (56.9\%), moderate $(29.7 \%)$, and chronic $(4.3 \%)$. Overall, these studies suggest that from 4 to $7 \%$ of children (especially boys) show a markedly high or chronic oppositional trajectory.

Although previous studies have underscored the heterogeneity of oppositional behavior in youth, the conclusions they have drawn should be considered with caution, given certain methodological specifics. First, the samples used differ in terms of age, sex, and risk status, and the longitudinal coverage varies considerably across studies (e.g., 4-74 months; 6, 10-15 years; 4-18 years). Second, to assess oppositional behavior, Bongers et al. (2004) based their study on mother's reports, whereas Petitclerc et al. (2009) used reports by the mother, father, and teacher, and Broidy et al., (2003) as well as Nagin and Tremblay (1999) used teachers' reports. Third, none of these studies modeled the trajectories while controlling for risk factors. Therefore, further studies in community samples are needed to enrich the knowledge on developmental changes in oppositional symptoms during elementary school. Through such studies, we believe that advances could be made in the body of knowledge on oppositional trajectories by including individual and familial risk factors as covariables when modeling trajectories. The capacity to characterize oppositional trajectories according to these two risk factor categories would be particularly useful for determining priority intervention targets in preschool, and for developing transition plans to meet the specific needs of children at risk for problems as they enter elementary school.

Family adversity, such as family structure and parental education, have frequently been associated with behavior problems (Côté, et al., 2007; Farris, Nicholson, Borkowski \& Whitman, 2011; Nagin \& Tremblay, 2001; Vitaro, Brendgen, Larose \& Tremblay, 2005) and failure to graduate from high school (Vitaro et al., 2005; Duchesne, Vitaro, Larose \& Tremblay, 2008). Several studies have also highlighted the association of parenting skills with behavior problems (Burke, Pardini \& Loeber, 2008; Harvey \& Metcalfe, 2012), meeting parental demands (Duchesne, Larose, Vitaro \& Tremblay, 2010), and the acquisition of prosocial behavior (Harvey \& Metcalfe, 2012). Finally, a number of studies have established clear connections between oppositional behavior and children's individual characteristics. In general, boys tend to be more oppositional than girls from early childhood onwards (Petitclerc et al., 2009; Drabick et al., 2011). Children who show excessive motor or verbal agitation and aggression are also more inclined to show oppositional behavior (Broidy et al., 2003; Nagin \& Tremblay, 1999; Maughan, Rowe, Messer, Goodman \& Meltzer, 2004). However, the relationship with anxiety is more complex. Whereas some authors found that anxiety and opposition were comorbid (Cunningham \& Ollendick, 2010; Drabick et al., 2011; Maughan et al., 2004), others have shown that anxiety was a protective factor against disruptive behavior (De Wall, Buckner, Lambert, et al., 2010; Kerr, Tremblay, Pagani \& Vitaro, 1997; Tremblay, Pihl, Vitaro \& Dobkin, 1994). These differences appear to depend on the type of anxious behaviors that are assessed.

The present study aimed to describe the developmental trajectories of opposition during the elementary school years and to identify two categories of predictors during kindergarten: familial characteristics (adversity, parental behavior) and children's personal characteristics (sex, opposition, hyperactivity, physical aggression, and anxiety). It is the first to model the trajectories of opposition symptoms on conditional risk factors. This longitudinal study had two objectives: 1) to describe oppositional behavior trajectories from the first to the sixth year of elementary school; and 2) to identify the risk factors during the kindergarten year that best discriminate children on the highest developmental trajectory of opposition during the elementary school years.

\section{Method}

\subsection{Participants and Procedure}

The participants of this study were drawn from the Quebec Longitudinal Study of Kindergarten Children (QLSKC). The sample comprised 1,929 children (958 boys, 971 girls) who attended public French kindergartens in the province of Quebec. For the first assessment (kindergarten), the average age of the children was 5.99 years $(\mathrm{SD}=.29)$. The majority of children spoke French $(94 \%)$ and lived with both biological parents $(82.9 \%)$. The mothers were 24.6 years old on average $(\mathrm{SD}=3.87)$ at the birth of their first child, and they had attended school for 11.9 years on average $(\mathrm{SD}=2.59$ ). In Quebec, students generally obtain a high school graduation certificate after 12 years of schooling (including kindergarten), provided they have not been held back for some reason, such as failing or repeating a grade. Initially, 6,397 students were randomly selected from the 11 administrative 
regions of Quebec, using a list provided by Quebec's ministry of education, leisure and sports (MELS). Of these, both parent and teacher of 4,648 returned questionnaires. Initial responders did not differ significantly from non-responders in terms of geographical location or school board size. Of these 4,648 children, 160 had formally withdrew from the study (156 refused to participate, 3 were severely handicapped, and 1 had died). One subgroup (1,929 children) was randomly selected from the group representative, and was assessed annually by their teachers and mothers from kindergarten to grade six in elementary school (Zoccolillo, Vitaro \& Tremblay, 1999).

Complete data were available for all the variables measured in kindergarten (T1). Concerning the oppositional behavior assessed from Time 2 to Time 7, we noted that complete data were available on 781 children (40.5\%), whereas a single data item was missing for 639 children (33.1\%), and at least two data items were missing for 509 of the sample $(26.4 \%)$. Nevertheless, the PROC TRAJ allows estimating missing values according to a maximum likelihood approach when at least two observations on the criterion variable are observable for that time point for each individual, and when the pattern of missing data is the type known as missing completely at random (MCAR; Jones et al., 2001; Jones, 2007). Little's MCAR test showed that the present data are MCAR $(\chi 2(257)=275.79, \mathrm{p}=.20)$. Thus, the missing data mechanism can be considered to be random or ignorable (Rubin \& Little, 2002).

\subsection{Measures}

\subsubsection{Oppositional Behavior and Personal Characteristics}

Oppositional behavior was assessed yearly from kindergarten to sixth grade by teachers with the Opposition subscale of the Social Behavior Questionnaire, teacher's version (SBQ-T; Tremblay, Loeber, Gagnon, Charlebois, Larivée \& Leblanc, 1991). This subscale contains five items that are consistent with the diagnostic criteria of the DSM-IV (Irritable. Easily upset - disobedient - does not share toys - blames others - inconsiderate of others) assessed on a three-point Likert scale ranging from 0 (never applies) to 2 (frequently applies). In the present study, the coefficient of internal consistency (Cronbach's alpha) varied from .79 to .83 between 6 and 11 years of age. Others studies with SBQ had similar coefficients (.74 to .84 for Broidy et al., $2003 ; .81$ to .84 for Nagin \& Tremblay, 1999; and .80 to 85 for Pingault et al., 2010).

The teachers also assessed the personal characteristics of the children in kindergarten using the Anxiety, Physical aggression, and Hyperactivity subscales of the SBQ-T. The Anxiety subscale contains six items (e.g., worries about many things; tends to be fearful or afraid of new things or new situations), the Physical aggression subscale contains three items (threatens or bullies others; bites; hits and kicks) and the Hyperactivity subscale contains two items (restless; squirmy). Internal consistency (Cronbach's alpha) ranged from . 74 for anxiety to .82 for physical aggression and .89 for hyperactivity. These coefficients are comparable to those reported by others (e.g., Broidy et al., 2003; Duchesne et al., 2008; Nagin \& Tremblay, 1999; Pingault et al, 2010).

\subsubsection{Familial Adversity}

A familial adversity index was created based on the data gathered from the mothers when their child entered kindergarten. Family structure (i.e., two-parent or single-parent), mother's age at the birth of her first child, and mother's number of years of education were used to construct the index. Each indicator was attributed a score of 0 or 1 according to the degree of adversity it presented for child. In the case of family structure, a child living with both biological parents obtained a score of 0 (low risk) while a child living within a single-parent unit or a blended family was assigned a score of 1 (higher risk). The other indicators (mother's education level and age at birth of first child) were given a score of 1 when the respective scores were in the bottom quartile and a score of 0 for higher values. At least two out of three indicators were required to create the index. The three indicators were then regrouped to build a global score labeled familial adversity (see Duchesne et al., 2008; Vitaro et al., 2005 for the detailed procedure). The higher the score (i.e., the closer to 1), the greater the degree of familial adversity. In this study, the average familial adversity was $.22(\mathrm{SD}=.28)$.

\subsubsection{Mother's Parenting Behavior}

The mother's parenting behavior was measured during the kindergarten year with the French version of the Emotional Climate for Children questionnaire (Falender \& Mehrabian, 1980). Two subscales were retained: Warmth and Control. The Warmth subscale contained 18 items (e.g., 'I never regret having a child'; 'I like to be with my child'; 'Having a child to care for is a lot of fun') and the Control subscale contained 16 (e.g., 'It is important for a child to have a fixed bedtime'; 'I don't tolerate temper tantrums'; 'Parents should not back down once they have told the child not to do something'). Each item was scored on a nine-point scale ranging from -4 (strongly disagree) to +4 (strongly agree). About warmth and control, a positive score for warmth indicates 
pleasure with their children and a negative score indicates displeasure with him/her. A positive score for control suggests a maternal dominance behavior opposite to a maternal submissiveness behavior (i.e. negative score) (Falender \& Mehrabian, 1980). Satisfactory evidence for discriminant validity was obtained for these subscales and for a parsimonious description of parental attitudes (Falender \& Mehrabian, 1980). In this study, the Cronbach's alpha was .79 for Warmth and .63 for Control.

\subsection{Statistical Analyses}

A model representing the optimal number of oppositional behavior trajectories was estimated using the PROC TRAJ procedure (Jones \& Nagin, 2007; Nagin, 1999) and the Bayesian Information Criterion (BIC) in SAS 9.0. Group-based trajectory is a specialized application of finite mixture modeling and is designed to identify clusters of individuals following similar progressions of some behavior over age (Jones \& Nagin, 2007). For each subgroup identified, each individual received a probability of belonging score that varied from 0 (low probability) to 1 (high probability). Probability was considered acceptable if it exceeded the .70 threshold (Nagin, 1999). The PROC TRAJ procedure also allows accounting for certain risk factors associated with the trajectories that affect the probability of belonging to a given subgroup (Jones \& Nagin, 2007). Familial characteristics (adversity, mother's warmth and control) and personal characteristics (aggression, anxiety, opposition, hyperactivity, and sex) in kindergarten were included as risk factors.

\section{Results}

Table 1. Bivariate correlations between familial and personal characteristics

\begin{tabular}{llllllllllllll}
\hline & Mean (SD) & 2 & 3 & 4 & 5 & 6 & 7 & 8 & 9 & 10 & 11 & 12 & 13 \\
\hline & & & & & & & & & & & & \\
Familial characteristics & & & & & & & & & & & \\
1. Adversity & $.22(.28)$ & .00 & -.11 & -.01 & .08 & .13 & .13 & .12 & .12 & .15 & .11 & .14 & .13 \\
2. Warmth & $14.46(6.29)$ & & .07 & .04 & -.05 & -.09 & -.13 & -.12 & -.07 & -.16 & -.13 & -.09 & -.14 \\
3. Control & $6.81(2.52)$ & & & -.01 & -.01 & .08 & .05 & .07 & .08 & .09 & .06 & .10 & .04
\end{tabular}

Child's personal characteristics

$\begin{array}{ll}\text { 4. Sex } & 1.50(.50) \\ \text { 5. Anxiety 6 yrs } & 2.18(2.31) \\ \text { 6. Phys. Aggress. 6 yrs } & .54(1.14) \\ \text { 7. Hyperactivity 6 yrs } & .91(1.28) \\ \text { 8. Opposition 6 yrs } & 1.42(2.04) \\ \text { 9. Opposition 7 yrs } & 1.35(1.99) \\ \text { 10. Opposition } 8 \text { yrs } & 1.27(1.87) \\ \text { 11. Opposition } 10 \text { yrs } & 1.29(1.94) \\ \text { 12. Opposition } 11 \text { yrs } & 1.16(1.81) \\ \text { 13. Opposition } 12 \text { yrs } & 1.20(1.79)\end{array}$

$\begin{array}{llllllllll}-.08 & -.26 & -.23 & -.22 & -.18 & -.17 & -.25 & -.24 & -.23\end{array}$
$\begin{array}{llllllll}.05 & .14 & .20 & .04 & .03 & .02 & .06 & .04\end{array}$ $\begin{array}{lllllll}.54 & .76 & .48 & .41 & .37 & .38 & .34\end{array}$ $\begin{array}{llllll}.60 & .35 & .34 & .34 & .27 & .27\end{array}$ $\begin{array}{lllll}.50 & .42 & .38 & .35 & .32\end{array}$ $\begin{array}{llll}.49 & .42 & .48 \quad .40\end{array}$ $.48 \quad .43 \quad .42$ $.48 \quad .42$

Note. Boys were used as the reference group. Correlations $\geq .04$ are significant at $p<.05$, and correlations $\geq .07$ are significant at $p<.01$.

Bivariate correlations were calculated to explore relationships between the variables examined. As shown in Table 1, most of the variables were significantly inter-correlated and in the expected direction. This suggests that oppositional behavior in kindergarten is associated with the child's familial and personal characteristics, with correlation coefficients ranging from -.23 to .76. In addition, the analysis reveals that the magnitude of the relationships between teacher-rated oppositional behaviors across the different school years is at its highest when 
only one year separates assessments (.48 to .52) and at its lowest (.32) when 5 years separates assessments.

\subsection{Opposition Trajectories}

The first objective was to identify oppositional behavior trajectories from the first to sixth year of elementary school. Group-based trajectory analyses were performed for two-group $(\mathrm{BIC}=-11445)$, three-group $(\mathrm{BIC}=$ -11333), and four-group models $(\mathrm{BIC}=-11339)$. Results indicated that the three-group model best fit the data (see Figure 1 below). Each line represents an oppositional behavior trajectory, calculated using average opposition scores in each identified trajectory. The average probability of belonging to a given trajectory varied from .83 to .87 .

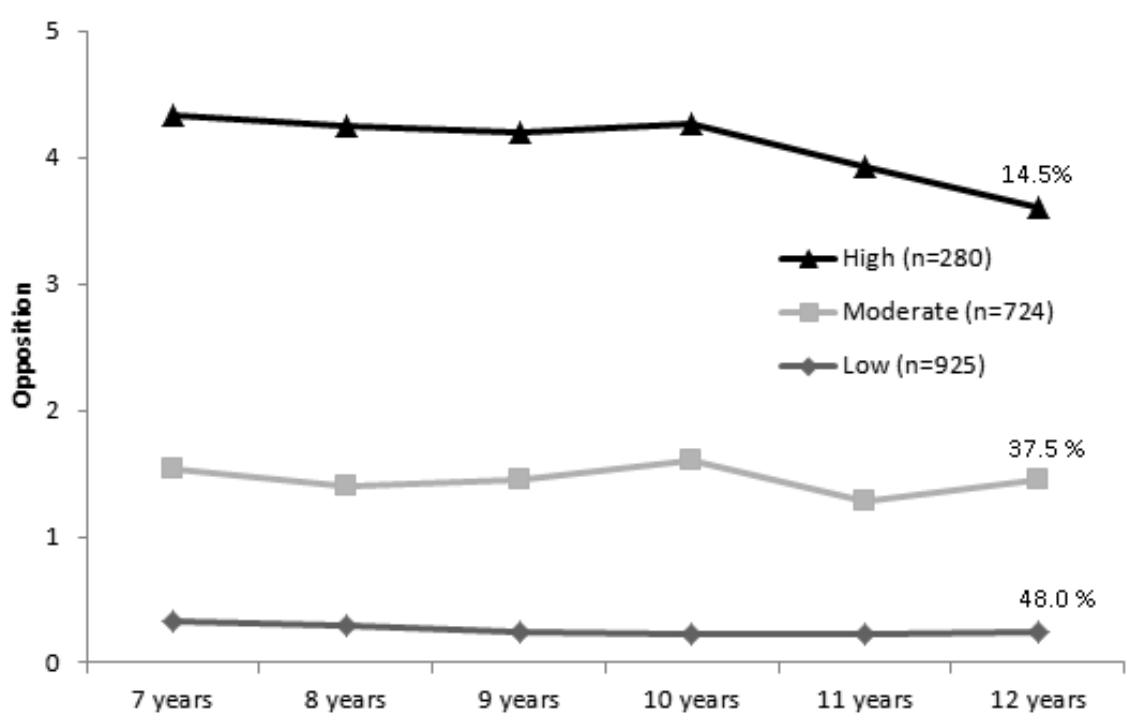

Figure 1. Opposition developmental trajectories in elementary school

The first group, Low Opposition (LO), accounts for $48.0 \%$ of the sample ( $\mathrm{n}=925 ; 31.1 \%$ boys). The linear parameter of this group's trajectory is statistically significant $(p<.01)$. These children were perceived by their teachers as showing little oppositional behavior, which tended to diminish through elementary school. The second group, Moderate Opposition (MO), accounts for $37.5 \%$ of the sample ( $n=724 ; 62.4 \%$ boys). The linear parameter is statistically significant $(p<.01)$. Compared to the other children in the sample, these children showed moderate oppositional behavior that varied slightly from first to sixth year of school. The third group, High Opposition (HO), accounts for $14.5 \%$ of the sample $(n=280 ; 77.9 \%$ boys $)$. This group contains the children that showed the most frequent oppositional behavior. The linear parameter of the trajectory $(p<.01)$ suggests that oppositional behavior decreased slightly in these children from first to sixth grade.

The results reveal three main findings. First, almost four boys for one girl showed a High Opposition trajectory (15.7\% of boys vs. $4.4 \%$ of girls). Second, almost half the boys (49.3\%) and over three-quarters of the girls (79.4\%) manifested very little oppositional behavior in class throughout elementary school. Third, despite a few variations over time and a slight decrease toward the end of elementary school, the three trajectories are relatively stable over the study period.

\subsection{Familial and Personal Characteristics Associated with Opposition Trajectories}

The second objective was to identify predictors of the trajectories that can be assessed during the kindergarten year. Familial adversity, mother' warmth and controlling parenting, as well as children's sex, physical aggression, hyperactivity, and anxiety at kindergarten were retained as predictors. The HO group was used as the reference for comparison with the MO and LO groups (see table 2). 
Table 2. Familial and personal characteristics associated with opposition trajectories

\begin{tabular}{lllllll}
\hline & \multicolumn{7}{c}{ HO vs. LO } & \multicolumn{5}{c}{ HO vs. MO } \\
\cline { 2 - 7 } Characteristics in kindergarten & Coefficient & Error & $t$ & Coefficient & Error & $t$ \\
\hline Familial characteristics & & & & & & \\
$\quad$ Adversity & -1.83 & .39 & $-4.62^{* *}$ & -1.01 & .35 & $-2.89^{* *}$ \\
$\quad$ Maternal warmth & .10 & .02 & $5.27^{* *}$ & .05 & .02 & $2.67^{* *}$ \\
$\quad$ Maternal control & .13 & .05 & $2.53^{*}$ & .16 & .05 & $3.48^{* *}$ \\
Childs' personal characteristics & & & & & & \\
$\quad$ Sex & 1.73 & .26 & $6.58^{* *}$ & .67 & .03 & $2.65^{* *}$ \\
$\quad$ Anxiety & .11 & .05 & $2.12^{*}$ & .01 & .05 & .24 \\
$\quad$ Physical aggression & -1.01 & .23 & $-4.39^{* *}$ & -.50 & .12 & -4.25 \\
$\quad$ Hyperactivity & -.53 & .12 & $-4.36^{* *}$ & -.08 & .09 & -.92 \\
$\quad$ Opposition & -.69 & .10 & $-6.67^{* *}$ & -.19 & .07 & $-2.82^{*}$ \\
\hline
\end{tabular}

${ }^{a}$ Boys serve as the reference group; Gender-based interactions revealed no significant relationships. ${ }^{* *} p<.01 ;{ }^{*} p<.05$.

HO vs. MO. Results revealed that children who were exposed to greater familial adversity in kindergarten had a higher probability of belonging to the $\mathrm{HO}$ group (coefficient $=-1.01, \mathrm{SE}=.35, p<.01$ ). Mother's lack of warmth (coefficient $=.05, \mathrm{SE}=.02, p<.01)$ and high control (coefficient $=.16, \mathrm{SE}=.05, p<.01)$ increased the probability of belonging to the $\mathrm{HO}$ group. Personal characteristics were also associated with the probability of belonging to the $\mathrm{HO}$ group. The greatest contributions were made by kindergarten teacher ratings of frequent physical aggression (coefficient $=-.50, \mathrm{SE}=.12, p<.01$ ) and opposition (coefficient $=-.19, \mathrm{SE}=.07, p<.01$ ). As expected, boys were more likely than girls to be on the HO trajectory compared to the MO trajectory (coefficient $=.67, \mathrm{SE}=.03, p<.01$ ). Kindergarten teacher ratings of hyperactivity and anxiety did not make significant contributions.

HO vs. LO. Analyses indicated that all the selected variables significantly distinguished the HO group from the LO group. Specifically, children exposed to greater familial adversity had higher odds of belonging to the HO group (coefficient $=-1.82, \mathrm{SE}=.39, p<.01$ ). The two maternal parenting characteristics, mother's lack of warmth (coefficient $=.10, \mathrm{SE}=.02, p<.01$ ) and mother's control (coefficient $=.13, \mathrm{SE}=.05, p<.01$ ), significantly increased the odds of belonging to the HO vs. LO group. Personal characteristics also distinguished the $\mathrm{HO}$ and LO groups: being a girl (coefficient $=1.73, \mathrm{SE}=.26, p<.01$ ) and kindergarten teacher rating of high anxiety (coefficient $=.11, \mathrm{SE}=.05, p<.05$ ) decreased the odds of belonging to the HO group. In contrast, high physical aggression (coefficient $=-1.01, \mathrm{SE}=.23, p<.01$ ), hyperactivity (coefficient $=-.53, \mathrm{SE}=.12, p<.01$ ) and opposition (coefficient $=-.69, \mathrm{SE}=.10, p<.01$ ) increased this probability. In other words, kindergarten boys who were assessed by their teachers as aggressive, defiant, hyperactive, and not very anxious were more likely to follow a high versus a low trajectory of oppositional behavior throughout elementary school.

\section{Discussion}

The first aim of the present study was to use a large population sample of elementary school boys and girls to trace three developmental trajectories of oppositional behavior using teacher ratings. These results are comparable to the findings of other researchers on developmental trajectories of oppositional symptoms (Bongers et al., 2004; Nagin \& Tremblay, 1999; Petitclerc et al., 2009), although their models include from four to six trajectories. We believe that this difference could be attributed to methodological differences. For example, although the five opposition items retained in our study were the same as those used in the study by Nagin and Tremblay, these researchers used a sample composed exclusively of boys who were at risk for oppositional behavior at 6 years and from 10 to 15 years of age. Moreover, the study by Bongers examined a sample of 13 cohorts of children and adolescents varying in age from 4 to 18 years, while Petitclerc and colleagues have traced developmental trajectories from 2.5 to 6 years. In addition, none of these studies considered familial or behavioral variables liable to affect the estimates of opposition trajectories.

Our results indicate that approximately $14.5 \%$ of children were on a high trajectory of oppositional behavior 
throughout elementary school, while the vast majority of children showed little or no oppositional behavior during this developmental period. These results clearly indicate continuity of frequent oppositional symptoms for a substantial number of children during the preschool and elementary school years. It is noteworthy that the average opposition score of the children in the high trajectory group was substantially higher than the average opposition score for the children on the two other developmental trajectories. Over a five year period the teachers systematically rated the children on the high trajectory as being frequently oppositional on three of the five symptoms used for the oppositional behavior scale while the DSM-IV diagnostic criteria for ODD requires only half of eight oppositional symptoms over a substantially shorter period of time (six months; APA, 2000). Although our method does not allow determining whether the children presented clinical symptoms of ODD, it is nevertheless noteworthy that they were distinguished from the other children by the intensity and persistence of their oppositional behavior from the time they first entered school. However, we should keep in mind that this oppositional behavior decreased slightly toward the end of elementary school, showing an improving trend.

The second aim of this paper was to identify early predictors of the high opposition trajectory during the elementary school years. Our results clearly show that risk of being on a high oppositional trajectory can be identified during the kindergarten year. The best risk factors assessed during the kindergarten year were teacher reported physical aggression and opposition, maternal reported high control and lack of warmth, family adversity and sex of the child (boys). Previous studies had shown that these variables are associated with oppositional problems at some point in development (Drabick et al., 2011; Côté et al., 2007; Farris et al., 2011), however this is the first study to clearly show that they can be used to identify kindergarten children who will be on a chronic oppositional trajectory during the whole course of the elementary school years. It is noteworthy that kindergarten teacher rated hyperactivity was not a significant predictor of the high versus medium opposition trajectories, once physical aggression and opposition were taken into account. This is probably because hyperactivity is highly correlated with physical aggression but less strongly correlated with chronic behavior problems than physical aggression (Broidy et al., 2003; Pingault et al., 2012). It is also important to note that the associations between opposition, physical aggression and hyperactivity do not start in kindergarten. This pattern of comorbidity develops during the first 24 to 42 months after birth, when frequency of physical aggression reaches its peak (Côté et al., 2007; Tremblay et al., 2004) and opposition is highly prevalent (Petitclerc et al., 2009).

The results also show that children who manifest certain signs of anxiety in kindergarten are less liable to be in the High Opposition trajectory up to the end of elementary school. Studies (Kerr et al., 1997; Tremblay et al., 1994) suggest that certain neurobiological characteristics that predispose children to anxiety could hinder the adoption of disruptive behavior. One characteristic of anxiety is that it tends to inhibit certain actions due to timidity and fear of unfamiliar situations (Kerr et al., 1997). This behavioral inhibition could cause a delay in the child's response, favoring a more considered response. This would in turn benefit the child in social interactions. However, although anxiety can act as a protective factor against oppositional behavior, the effect does not appear to extend beyond elementary school (Mason, Kosterman, Hawkins, Herrenkohl, et al., 2004). Nevertheless, we should keep in mind that manifestations of anxiety are significant risk factors for the appearance and maintenance of adaptation problems throughout development (Polier, Vloet, Herpetz-Dahlmann, Laurens \& Hodgins, 2011).

\subsection{Implications}

The description of oppositional behavior trajectories during the elementary school years and the identification of risk factors during kindergarten are important for planning preventive interventions. Our results indicate that preventive interventions starting in kindergarten should specifically target boys who are physically aggressive and oppositional, especially if they are from high adversity families. Maternal parenting skills, such as control and warmth, can also be used as additional risk factors, and possibly as targets for parenting skills interventions. Intensive support to these children, their families and teachers has been shown to ameliorate parenting skills, increase high school completion and reduce criminal behavior during early adulthood (Vitaro, Barker, Brendgen \& Tremblay, 2012). Kindergarten gathers all types of children together and provides a privileged environment, including the services of psychologists and social workers, who can intervene not only with the children, but also with their parents. However, because behavior problems such as opposition, aggression and hyperactivity are present by the end of the first year after birth, preventive interventions are also needed long before children start kindergarten (Tremblay, 2010). A number of studies have shown that family interventions should address both parenting skills and the use of social reinforcement (McMahon, Long \& Forehand, 2010; Webster-Stratton, Reid \& Hammond, 2004). More specifically, parental interventions should bear on positive relationships and interactions with their children, with fewer coercive measures. Children would benefit from interventions that target social skills, problem solving, and social attributions (Webster-Stratton et al., 2004). To be effective, 
interventions should aim to train both parents and children. Not only are the outcomes better, they also appear to be sustained over time (Webster-Stratton et al., 2004).

\subsection{Limitations}

This study has limitations that need to be taken into account. First, the results are based on a sample of children recruited from a French-speaking community in North America. Second, the correlational design of the study does not allow separating the reciprocal effect of children's and parents' characteristics. Clearly, unidirectional relationships could also be inverted. On this topic, some researchers (e.g., Burke et al., 2008) have argued that the development of oppositional behavior may be viewed from a transactional perspective, whereby it is possible that children with more difficult temperaments could influence their parents' behavior. Finally, only maternal parenting was assessed. Studies are needed to explore father's role in the development and prevention of oppositional behavior problems during childhood. Finally, the sex differences observed in this study and others may be due to the fact that the tendency to defy parents, siblings, peers, and teachers develops later in girls than in boys (Maughan et al., 2004). Other studies (Vitaro et al., 2012) also suggest that girls may express their opposition in more passive ways. For example, they might be petty, refuse to obey an order, pout, be resentful, complain about carrying out a task, or remain silent to conceal their displeasure. Because the items used in this study did not allow measuring more passive manifestations of oppositional behavior, we may have underestimated girls' opposition. Further studies are needed to refine our understanding of girls' oppositional development.

\subsection{Conclusion}

Although numerous studies of oppositional behavior have been conducted, few longitudinal studies have addressed its development in community samples of boys and girls during the elementary school years. Indeed this study is the first to trace the developmental trajectories of oppositional behavior from 6 to 12 years and to identify the kindergarten predictors of the high opposition trajectory. The overall results of the present study bring new insight into the association between children's oppositional symptoms during elementary school years and certain familial and personal risk factors that can be assessed during kindergarten. Our findings call for research on the prevention of these problems during preschool and the early elementary school years.

\section{References}

Bongers, I. L., Koot, H. M., van der Ende, J., \& Verhulst, F. C. (2004). Developmental trajectories of externalizing behaviors in childhood and adolescence. Child Development, 75, 1523-1537. http://dx.doi.org/10.1111/j.1467-8624.2004.00755.x

Broidy, L. M., Nagin, D. S., Tremblay, R. E., Bates, J. E., Brame, B., Dodge, K. A., Fergusson, ... Vitaro, F. (2003). Developmental trajectories of chilhood disruptive behaviors and adolescent delinquency: A six-site, $\begin{array}{lllll}\text { cross-national study. } & \text { Developmental } & \text { Psychology, } & 39, & \text { 222-25. }\end{array}$ http://dx.doi.org/10.1037/0012-1649.39.2.222

Burke, J. D., Pardini, D., \& Loeber, R. (2008). Reciprocal relationships between parenting behavior and disruptive psychopathology from childhood through adolescence. Journal of Abnormal Child Psychology, 36, 679-692. http://dx.doi.org/10.1007/s10802-008-9219-7

Burke, J. D., Waldman, I., \& Lahey, B. B. (2010). Predictive validity of childhood oppositional defiant disorder and conduct disorder: Implications for DSM-V. Journal of Abnormal Psychology, 119, 739-751. http://dx.doi.org/10.1037/a0019708

Côté, S. M., Boivin, M., Nagin, D. S., Japel, C., Xu, Q., Zoccolillo, ... Tremblay, R. E. (2007). The Role of Maternal Education and Nonmaternal Care Services in the Prevention of Children's Physical Aggression Problems. Archives of General Psychiatry, 64, 1305-1312. http://dx.doi.org/10.1001/archpsyc.64.11.1305

Cunningham, N. R., \& Ollendick, T. H. (2010). Comorbidity of anxiety and conduct problems in children: Implications for clinical research and practice. Clinical Child and Family Psychology Review, 13, 333-347. http://dx.doi.org/10.1007/s10567-010-0077-9

De Wall, C. N., Buckner, J. D., Lambert, N. M., Cohen, A. S., \& Fincham, F. D. (2010). Bracing for the worst, but behaving the best: Social anxiety, hostility, and behavioral aggression. Journal of Anxiety Disorders, 24, 260-268. http://dx.doi.org/10.1016/j.janxdis.2009.12.002

Drabick, D. A., Bubier, J., Chen, D., Price, J., \& Lanza, H. I. (2011). Source-specific oppositional defiant disorder among inner-city children: Prospective prediction and moderation. Journal of Clinical Child and Adolescent Psychology, 40, 23-35. http://dx.doi.org/10.1080/15374416.2011.533401 
Duchesne, S., Larose, S., Vitaro, F., \& Tremblay, R. E. (2010). Trajectories of anxiety in a population sample of children: Clarifying the role of children's behavioral characteristics and maternal parenting. Developmental Psychopathology, 22, 361-373. http://dx.doi.org/10.1017/S0954579410000118

Duchesne, S., Vitaro, F., Larose, S., \& Tremblay, R. E. (2008). Trajectories of anxiety during elementary-school years and the prediction of high school noncompletion. Journal of Youth and Adolescence, 37, 1134-1146. http://dx.doi.org/10.1007/s10964-007-9224-0

Falender, C. A., \& Mehrabian, A. (1980). The emotional climate for children as inferred from parental attitudes: A preliminary validation of three scales. Educational and Psychological Measurement, 40, 1033-1042. http://dx.doi.org/10.1177/001316448004000430

Farris, J. R., Nicholson, J. S., Borkowski, J. G., \& Whitman, T. L. (2011). Onset and progression of disruptive behavior problems among community boys and girls: A prospective longitudinal analysis. Journal of Emotional and Behavioral Disorder, 19, 233-247. http://dx.doi.org/10.1177/1063426610370746

Gale, B. M. (2011). Oppositional defiant disorder. In W. T. O'Donohue, \& C. Draper (Eds.), Stepped care and e-Health: Pratical implications to behavioral disorders. (pp. 181-202). New York: Springer Science.

Harvey, E. A., Friedman-Weieneth, J. L., Goldstein, L. H., \& Sherman, A. H. (2007). Examining subtypes of behavior problems among 3-years-old children, Part 1: Investigating validity of subtypes and biological risk-factors. Journal of Abnormal Child Psychology, 35, 97-110. http://dx.doi.org/10.1007/s10802-006-9087-y

Harvey, E. A., \& Metcalfe, L. A. (2012). The Interplay Among Preschool Child and Family Factors and the Development of ODD Symptoms. Journal of Clinical Child \& Adolescent Psychology, 41, 1-13. http://dx.doi.org/10.1080/15374416.2012.673161

Jones, B. L. (2007). Proc Traj: A SAS procedure for group based modeling of longitudinal data [PowerPoint slides]. Retrieved from https://apha.confex.com/apha/135am/techprogram/paper_165793.htm

Jones, B. L., \& Nagin, D. S. (2007). Advances in group-based trajectory modeling and an SAS procedure for estimating them. Sociological Methods \& Research, 35, 542-571. http://dx.doi.org/10.1177/0049124106292364

Kerr, M., Tremblay, R. E., Pagani, L., \& Vitaro, F. (1997). Boys' behavioral inhibition and the risk of later delinquency. Archives of General Psychiatry, 509-816. http://dx.doi.org/10.1001/archpsyc.1997.01830210049005

Kimonis, E. R., \& Frick, P. J. (2010). Etiology of oppositional defiant disorder and conduct disorder: Biological, familial and environmental factors identified in the development of disruptive behavior disorders. In R. C. Murrihy, A. T. Kidman, \& T. H. Ollendick (Eds.), Clinical handbook of of assessing and treating conduct problems in youth (pp. 49-76). New York: Springer. http://dx.doi.org/10.1007/978-1-4419-6297-3_7

Mason, W. A., Kosterman, R., Hawkins, J. D., Herrenkohl, T. I., Lengua, L., \& Mccauley, E. (2004). Predicting depression, social phobia, and violence in early adulthood from child behavior problems. Journal of the American Academy of Child and Adolescent Psychiatry, 43, 307-315. http://dx.doi.org/10.1097/00004583-200403000-00012.

McMahon, R. J., Long, N., \& Forehand, R. L. (2010). Parent training for the treatment of oppositional behavior in young children: Helping the noncompliant child. In R. C. Murrihy, A. D. Kidman, \& T. H. Ollendick (Eds.), Clinical handbook of assessing and treating conduct problems in youth (pp. 163-191). New York: Springer. http://dx.doi.org/10.1007/978-1-4419-6297-3_7

Maughan, B., Rowe, R., Messer, J., Goodman, R., \& Meltzer, H. (2004). Conduct disorder and oppositional defiant disorder in a national sample: Developmental epidemiology. Journal of Child Psycholology and Psychiatry, 45, 609-621. http://dx.doi.org/10.1111/j.1469-7610.2004.00250.x

Munkvold, L. H., Lundervold, A. J., \& Manger, T. (2011). Oppositional defiant disorder - Gender differences in co-occuring symptoms of mental health problems in a general population of childre. Journal of Abnormal Child Psychology, 39, 577-587. http://dx.doi.org/10.1007/s10802-011-9486-6

Nagin, D. S. (1999). Analyzing developmental trajectories: A semiparametric, group-based approach. Psychological Methods, 4, 139-157. http://dx.doi.org/10.1037/1082-989X.4.2.139

Nagin, D. S., \& Tremblay, R. E. (1999). Trajectories of boys' physical agression, opposition, and hyperactivity on the path to physically violent and nonviolent juvenile delinquency. Child Development, 70, 1181-1196. 
http://dx.doi.org/10.1111/1467-8624.00086

Nagin, D. S., \& Tremblay, R. E. (2001). Parental and early childhood predictors of persistent physical aggression in boys from kindergarten to high school. Archives of General Psychiatry, 58, 389-394. http://dx.doi.org/10.1001/archpsyc.58.4.389

Petitclerc, A., Boivin, M., Dionne, G., Zoccolillo, M., \& Tremblay, R. E. (2009). Disregard for rules: The early development and predictors of a specific dimension of disruptive behavior disorders. Journal of Child Psychology and Psychiatry, 50, 1477-1484. http://dx.doi.org/10.1111/j.1469-7610.2009.02118.x

Pingault, J.-B., Côté, S. M., Galéra, C., Genolini, C., Falissard, B., Vitaro, F., \& Tremblay, R. E. (2012). Childhood trajectories of inattention, hyperactivity and oppositional behaviors and prediction of substance abuse/dependence: A 15-year longitudinal population-based study. Molecular Psychiatry, june, 1-7. http://dx.doi.org/10.1038/mp.2012.87

Polier, G. G., Vloet, T. D., Herpetz-Dahlmann, B., Laurens, K. R., \& Hodgins, D. (2011). Comorbidity of conduct disorder symptoms and internalising problems in children: Investigating a community and a clinical sample. European Child and Adolescent Psychiatry, 21, 31-38. http://dx.doi.org/10.1007/s00787-011-0229-6

Tremblay, R. E. (2010). Developmental origins of disruptive behaviour problems: The 'original sin' hypothesis, epigenetics and their consequences for prevention. Journal of Clinical Child and Adolescent Psychology, 51, 341-367.http://dx.doi.org/10.1111/j.1469-7610.2010.02211.x

Tremblay, R. E., Loeber, R., Gagnon, C., Charlebois, P., Larivée, S., \& LeBlanc, M. (1991). Disruptive boys with stable and unstable high fighting behavior patterns during junior elementary school. Journal of Abnormal Child Psychology, 19, 285-300. http://dx.doi.org/10.1007/BF00911232

Tremblay, R. E., Nagin, D. S., Séguin, J. R., Zoccolillo, M., Zelazo, P. D., Boivin, M., ... Japel, C. (2004). Physical aggression during early childhood: Trajectories and predictors. Pediatrics, 114, 43-50. http://dx.doi.org/10.1542/peds.114.1.e43

Tremblay, R. E., Pihl, R. O., Vitaro, F., \& Dobkin, P. L. (1994). Predicting early onset of male antisocial behavior from preschool behavior. Archives of General Psychiatry, 51, 732-739. http://dx.doi.org/10.1001/archpsyc.1994.03950090064009

Vitaro, F., Barker, E. D., Brendgen, M., \& Tremblay, R. E. (2012). Pathways Explaining the Reduction of Adult Criminal Behaviour by a Randomized Preventive Intervention for Disruptive Kindergarten Children. $\begin{array}{llllll}\text { Journal of Child Psychology and Psychiatry, } & \text { 53, }\end{array}$ http://dx.doi.org/10.1111/j.1469-7610.2011.02517.x

Vitaro, F., Brendgen, M., Larose, S., \& Tremblay, R. E. (2005). Kindergarten disruptive behaviors, protective factors, and educational achievement by early adulthood. Journal of Educational Psychology, 97, 617-629. http://dx.doi.org/10.1037/0022-0663.97.4.617

Webster-Stratton, C., Reid, M. J., \& Hammond, M. (2004). Treating children with early-onset conduct problems: Intervention outcomes for parent, child, and teacher training. Journal of Clinical Child \& Adolescent Psychology, 33, 105-124. http://dx.doi.org/10.1207/S15374424JCCP3301_11

Zoccolillo, M., Vitaro, F., \& Tremblay, R. E. (1999). Problem drug and alcohol use in a community sample of adolescents. Journal of the American Academy of Child and Adolescent Psychiatry, 38, 900-907. http://dx.doi.org/10.1097/00004583-199907000-00021 